\title{
AC 2007-2644: ENGINEERING ENTREPRENEURSHIP ? A KILLER APP FOR SE ?
}

\section{Carmo D'Cruz, Florida Tech}

Dr. Carmo D'Cruz is Associate Professor of Engineering Enttrepreneurship in the Department of Engineering Systems at Florida Tech. He has over 20 years of industrial experience at Bell Labs,Advanced Micro Devices, Hitachi Semiconductor, RF Monolithics, Harris Semiconductor, Tantivy Communications and Chip Supply Inc. in addition to teaching experience in the Business and Engineering Schools at the University of Central Florida in Orlando.

\section{Dr. Shoaib Shaikh, Nothrup Grumman Corporation}

Dr. Shoaib Shaikh is a Staff Engineer at Northrop Grumman Corporation in Melbourne. He has his PhD from Florida Tech. He is currently completing his Master's degree in Systems Engineering from Florida Tech. He regularly participates in Florida Tech outreach and experiential entrepreneurship activities 


\title{
Engineering Entrepreneurship: A Killer App for Systems Engineering?
}

\begin{abstract}
Engineering Entrepreneurship, Engineering Management and Systems Engineering courses offered by the Department of Engineering Systems at Florida Tech have greatly enriched the students' educational experience, broadened their perspectives, served as community outreach forums and integrated experiential learning with academic programs. Students work in E-teams and write NCIIA proposals to commercialize innovative product or university/research lab developed technology.

This paper describes a unique course series in Systems Engineering (SE) Entrepreneurship. Innovation in product/service design and commercialization that enables entrepreneurship can be successfully leveraged by applying SE principles/ techniques which parallel entrepreneurship steps such as Customer Requirements Engineering and opportunity recognition; Project/Quality Engineering, Decision/Risk Analysis, Systems Modeling, Engineering Economics and business planning, Systems Integration and business plan development, Systems Launch considerations and product/business launch, etc. Concepts in strategy, team dynamics, and finance are integrated into these courses focusing on Engineering Entrepreneurship. It appears that Engineering Entrepreneurship has emerged as a Killer App for Systems Engineering.
\end{abstract}

\section{Introduction}

The emerging facts from successful organizations, including universities, indicate that the real source of power in a knowledge economy is in combining technical prowess with entrepreneurship. ${ }^{1}$ A survey of business executives and managers indicated that highly successful engineers are not only academically astute, but also possess entrepreneurial skills. ${ }^{2}$ The Engineers of 2020 will need to be educated as innovators, with more direct exposure to crossdisciplinary topics and the workings of an entrepreneurial economy. ${ }^{3}$ However, engineering schools have been slow to incorporate entrepreneurship courses into the technical programs.

A common complaint heard from most high tech entrepreneurs is that their entrepreneurial projects always take more than $2 \mathrm{X}$ the time, $2 \mathrm{X}$ the money and $2 \mathrm{X}$ the resources than what they planned for at the outset. ${ }^{4}$ It has been observed that most successful high tech and serial entrepreneurs have a systems engineering approach to their entrepreneurial ventures. ${ }^{5}$ The economy in which the Engineers of 2020 will work will be strongly influenced by the global marketplace for engineering services and a growing need for interdisciplinary and system-based approaches. 6 While meeting the increasing demand for holistic, interdisciplinary education, innovative courses offered by Florida Tech's Department of Engineering Systems have greatly enriched the students' educational experience, broadened their perspectives, served as community outreach/ networking forums and integrated experiential learning with academic programs. 
This paper describes a pioneering, innovative new course in Systems Engineering Entrepreneurship that is dove-tailed into three existing courses in Technical Marketing, High Tech Product Strategy and Technology Commercialization Strategies ${ }^{7}$ to complete a course series and proposed certificate program in Systems Engineering Entrepreneurship. The Systems Engineering Entrepreneurship course which has received excellent reviews from students, is being taught for a second successive semester at Florida Tech. This course is uniquely designed to leverage proven Systems Engineering principles, tools and practices that parallel entrepreneurship concepts and steps for high tech entrepreneurial success such as Requirements Engineering, Competitive Analysis, Systems Modeling and Simulation, Product Development Process Engineering, Project Engineering, Decision and Risk Analysis, Systems Integration, Performance Assessment, System Launch Considerations, System Life-Cycle Costing, Quality Engineering, etc.

As part of the course and program requirements, students work in E-teams which can include outside technical experts as team members or advisors. The E-teams seek funding by completing NCIIA Advanced E-team proposals ${ }^{8}$ or SBIR/STTR proposals and presenting their business plans at investor-attended colloquiums and competitions.

It is anticipated that the pioneering Systems Engineering Entrepreneurship course and program, with its rigorous cutting edge SE tools and techniques especially in Technology Function Deployment, Requirements Engineering, Project Engineering, Decision and Risk Analysis, and Simulation will create new paradigms in entrepreneurship education and will enable the entrepreneurial high tech endeavors of engineers to be more deterministic than stochastic and greatly enhance the chances of entrepreneurial success. An expected secondary outcome of this program is the shift of the locus of entrepreneurship education from the traditional business schools (which have had limited success in launching highly successful high tech start-ups) to the engineering schools (which have traditionally been responsible for the sources of most (>90\%) of the successful high tech companies). ${ }^{9}$

\section{Engineering and Teaching of Entrepreneurship}

Engineers with a Bachelor or Master degree are typically products of a four-year and two-year university programs respectively, which vary little from university to university, or even country to country. Entrepreneurial courses can be found in high schools, undergraduate schools, graduate schools, trade associations, private establishments, short courses, and correspondence courses. Although there is some agreement on the skills and characteristics needed for entrepreneurial behavior, there is no consensus on how best to impart the knowledge. ${ }^{10}$

The field of "Teaching of Entrepreneurship" in business schools has been divided as to whether entrepreneurship can be taught or not. ${ }^{11}$ A more appropriate emerging question is "Can Entrepreneurs Learn?"12 Those who favor Entrepreneurship as an independent academic discipline see it as a distinctive, if not unique component of the free enterprise system. In this respect, it creates wealth, improves the productivity of a region, adds to employment, and offers a more exciting dimension to society. A second consideration is that entrepreneurship contains specific knowledge, concepts and theories that apply in a reasonable and consistent manner across the discipline. The search for an opportunity, the verification or viability of the 
opportunity and the language of financing are distinct and particular to entrepreneurship in its own right. ${ }^{13}$ Those who do not favor an entrepreneurship discipline are becoming less vocal in their opposition than in the past. Entrepreneurship courses and programs are sprouting up in business and engineering colleges of esteemed universities. What does remain is the lingering argument that much of what is applied in the process of entrepreneurship includes material that overlaps in other courses. ${ }^{14}$

In the early days, a number of large universities claimed that the functions of management planning, organizing, controlling- are very much evident in entrepreneurship and need not be treated as a uniquely different discipline. The debate did not recognize two critically important features of an entrepreneur: The role of creativity in entrepreneurship, whereby the new concept, invention and innovation that literally takes charge of the entrepreneur. Second, there is the vision that goes along with the new concept. A final argument that the more conservative academics pursued was that, since a new venture cannot really be created in the classroom, the concept of entrepreneurship cannot be taught and that the "concept of starting one's own business" does not require academic treatment. However, teaching entrepreneurship offers advantage of avoiding those errors and misjudgments made by individuals who ventured before. ${ }^{19}$

The academic propositions in teaching business to young people also apply in the teaching of entrepreneurship. The number of businesses created and the economic impact of entrepreneurship courses and programs at Stanford, MIT, University of Texas-Austin and other leading universities is testimony to the fact that entrepreneurship skills and know-how can be taught and entrepreneurs can be nurtured through supporting programs in university-based incubators, entrepreneur associations and local business networks. ${ }^{15,16,17,18}$

\section{Important Factors Impacting New Venture Creation}

Benjamin Mokry $^{20}$ suggests that in order to create a more receptive environment for entrepreneurship, a number of fundamental societal changes must occur. He supports the major truism that "local communities are the breeding ground of entrepreneurship" and are capable of creating environments favorable to it. Mokry has emphasized two factors that affect entrepreneurial success: 1) Existence of an entrepreneurial sub-culture. The tremendous success of Silicon Valley, Boston, Austin and San Diego very much support the notion that entrepreneurs feed off each other in a synergistic fashion and create their own dynamic environment. 2) Incubators and Entrepreneur Support Organizations (ESOs), many of which are initiated by local universities/governments as enterprise centers.

Recent studies have developed a more positive awareness of educating people in entrepreneurship and eventually how to become entrepreneurial. It has been determined that 1) potential entrepreneurs can be encouraged through university-based entrepreneurship programs 2) entrepreneurship within an established definition can be taught and 3) entrepreneurial alumni do succeed and they themselves provide further insights and educational materials for dissemination in the classroom. ${ }^{21,22,}{ }^{23}$ Studies by Wolfe, Adkins and Sherman, ${ }^{24}$ have shown that universities serve as sources of new technologies that might be commercialized by incubator client firms and other regional start-ups. Universities can also provide other valuable services 
and unique resources to both the incubator, its clients and other regional start-ups such as (1) Faculty / technologist managerial or technical consulting on a pro bono or fee basis (2) Student interns and employees (3) Access to technical labs, facilities and equipment (4) Access to databases and researchers (5) Access to research and development financing through programs such as SBIR - federal grant funding is greatly enhanced when incubator clients submit a joint proposal with a university or federal laboratory (6) Additional services and resources including patent knowledge, alumni who may act as advisors, business contacts and strategic alliance facilitators or investors, access to a far-flung network of laboratories and technical expertise, and access to investment by university foundations.

All the above mentioned research findings and other issues and environmental factors were considered when designing the engineering entrepreneurship programs at Florida Tech. Additionally, leading entrepreneurship programs in the country were benchmarked and the best practices were adopted. ${ }^{25,26,27,28,29}$

\section{Why Systems Engineering Entrepreneurship?}

Henry Ford can be considered a pioneer in the field of Systems Engineering Entrepreneurship. In 1902, the initial investors forced Henry Ford out of the Henry Ford Company they had established to manufacture the car that Henry had designed. They wanted to manufacture small quantities of expensive cars for the upper echelons of society. They re-christened the company the Cadillac Automobile Company and went on to modest success. Henry started the Ford Motor Company and designed and manufactured the Model $\mathrm{T}$ for the masses using systems engineering principles of proactive product standardization, quality, manufacturability, mass marketability, etc and with its resounding success, he changed the auto industry and the American lifestyle. ${ }^{30}$

Traditionally, engineers in the various disciplines have been trained to solve explicit problems, such as finding the solutions of n-equations with n-unknowns. In such problems all the required information is provided, and the solution requires the application of a specific strategy that will work for all problems of a given type. Unfortunately, the nature of the $21^{\text {st }}$ century economy means that the types of problems that engineers have to solve tend to be more implicit in form. All the information required for the solution is available, but it is fragmented, dispersed and requires highly developed perception skills to extract and use successfully. Traditionally, in large corporations, high levels of creativity and innovative idea generation have not been seen as central to the engineer's role. However, to compete in a changing marketplace fraught with rapidly changing technology, shorter product life-cycles, downsizing and outsourcing, engineers need to re-invent themselves as independent and entrepreneurial and market their creativity. ${ }^{31}$ In many large corporations, entrepreneurially thinking engineers have been observed to show more entrepreneurial initiative and a higher level of productivity, efficiency and cost-consciousness. It is a known fact that engineers who manage their engineering careers as entrepreneurs from the start enjoy a higher probability of advancing within the company. ${ }^{32}$ The Systems Engineering and Engineering Management degree programs at Florida Tech broaden the typical engineer's perspectives considerably with the traditional well-rounded Engineering Management and Systems Engineering course offerings, as well as complementary innovative courses in Technical Marketing, High Tech Product Strategy, Systems Engineering Entrepreneurship and Technology 
Commercialization Strategies to produce "The Engineer of 2020" as described by the National Academy of Engineering. ${ }^{6}$

Despite the popularity of these engineering entrepreneurship-related courses, the word "entrepreneur" is often misunderstood by engineers and some employers as it conjures visions of larger than life empire-builders who create high risk business ventures that promise either intoxicating wealth or wretched bankruptcy - and very little in between. Entrepreneurs seem to thrive in chaotic and uncertain realms, far removed from the orderly and methodical world of engineers, where calculations and data are applied to design solutions that eliminate uncertainty and risk. Another misperception is that entrepreneurship courses belong to business schools and are not engineering-related. However, the truth is that Engineering Principles parallel Entrepreneurship Concepts. All employers are engaged in a business to produce a return on investment. An engineer's compensation package is an investment made by the company. Whether one is a CEO in charge of a whole company or an engineer overseeing a single task or project, he or she is responsible for producing a positive return on the investments they are entrusted to. So all engineers engage in entrepreneurship - but only those who deliver the best returns on the investment they manage will be in the best positions for advancement. ${ }^{31,32}$

\section{Taxonomy of Engineers, Promoters, Managers, Engineering Managers,Engineering Entrepreneurs and Systems Engineering Entrepreneurs}

(Adapted from: Jeffry Timmons' New Venture Creation)

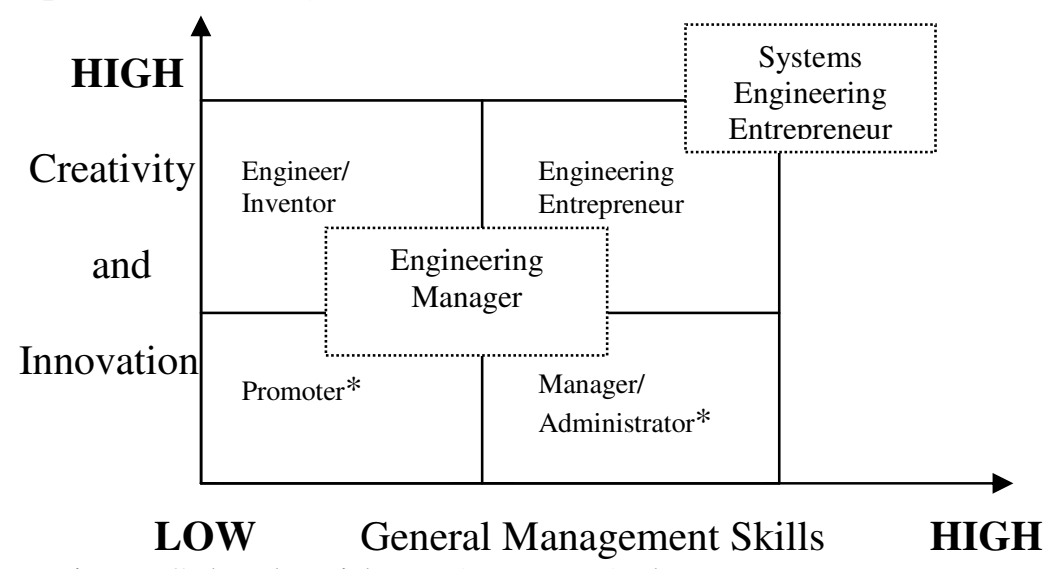

* Typical graduates of Business Schools with BBA or MBA degrees

The taxonomy above illustrates the relative skills and characteristics of Engineers, Promoters, Managers, Engineering Managers, Engineering Entrepreneurs and graduates of Systems Engineering Programs. As a result of the interdisciplinary nature of the Engineering Management program and his/her engineering education and experience, the typical Engineering Management graduate is expected to have higher levels of Creativity and Innovation capabilities than the typical Promoter and Management graduates of Business school BBA/MBA programs. The Engineering Entrepreneur with a broad based entrepreneurially-oriented engineering education rooted heavily in experiential entrepreneurship programs and activities is expected to develop a higher level of skill sets in Creativity and Innovation as well as general management skills, business know-how and networking skills. Armed with a cache of Systems Engineering tool and techniques such as simulation, project engineering, systems integration, Technology Function Deployment, customer requirement engineering, decision and risk analysis, etc that 
make the entrepreneurial process more deterministic and after going through a broad based entrepreneurially-oriented engineering education rooted heavily in experiential entrepreneurship programs and activities, the Systems Engineering Entrepreneur graduates have demonstrated the highest levels of creativity and innovation and general management skills, business know-how and networking skills.

A common complaint heard from most high tech entrepreneurs is that their entrepreneurial projects always take more than $2 \mathrm{X}$ the time, the money and the resources than what they planned for at the outset. The Systems Engineering Entrepreneurship course at Florida Tech is designed to allay the above misperceptions, fears and complaints using proven Systems Engineering body of knowledge in Project Engineering, Systems Integration, Decision and Risk Analysis, Simulation, Systems Life-Cycle Costing, etc. It has been observed that some of the most successful high tech and serial entrepreneurs have a systems engineering approach to their entrepreneurial ventures. This is because of their broad perspective of the competitive environment and a balanced, methodical and systematic approach to capitalize on the opportunities to ensure sustained long term success. (See course description in the Appendix).

The influence of Systems Engineering (SE) thinking on entrepreneurship has often been overlooked in business-school based technological entrepreneurship programs. The innovation process is significantly improved and made more robust by adopting a SE mindset early in the timeline. If SE concepts that work so well in engineering are applied to the innovation process, the quality of the innovation and likelihood of success are improved by significant orders of magnitude. For example potential investors will look more favorably on a product concept that has a lifecycle design effort put into the initial model. This leads to a more mature product development process that is less likely to run into development troubles. Therefore the investors will see a more desirable opportunity and the entrepreneur significantly improves the probability of entrepreneurial success.

\section{Goals of the Systems Engineering Entrepreneurship Program:}

The Systems Engineering Entrepreneurship Program has 5 major goals:

1. Provide a unique, systems engineering - based encouraging environment for engineers to ease into careers in entrepreneurship and create investable, start-up, technology-based ventures that will create jobs and function as sustainable, revenue generating high tech companies on the Space Coast.

2. Experience the process of engineering entrepreneurship from a Systems Engineering perspective - by identifying and pursuing a business opportunity for a technology / product with a team of motivated peers and entrepreneur support groups from the community - even if they decide not to pursue entrepreneurial careers eventually, this experience will make them more effective entrepreneurs in their organizations

3. Using a Systems Engineering approach, systematically learn how to structure and develop a business that is attractive to investors and develop products that are popular with customers.

4. Use System Engineering principles and techniques to analyze and alleviate the problems encountered in starting up a technology-based venture with very high degrees of technical and market uncertainties 
5. Meet practicing professionals and learn from the experiences of seasoned entrepreneurs, investors and business service providers to get feedback and valuable insights from professionals and acquire practical knowledge and tools

\section{4-Course Florida Tech Systems Engineering Entrepreneurship Program}

The Systems Engineering Entrepreneurship course series and program consists of one new course module in Systems Engineering Entrepreneurship that is dove-tailed into three existing course modules in Technical Marketing, High Tech Product Strategy and Technology Commercialization Strategies.

Module 1: Systems Engineering Entrepreneurship - this module is a comprehensive overview of Systems Engineering Principles as applied to Engineering Entrepreneurship and the students will start integrating the various components to develop their business plan. The risks, rewards and challenges of entrepreneurship, and the system-engineering-based strategies and tactics to increase the chances of success are systematically covered in this module. Each session of this module consists of (1) a lecture and case study based on system engineering principles that parallel an entrepreneurship concept and step and (2) experiential guest lecture/seminar by industry expert or entrepreneur on entrepreneurial opportunities in emerging fields.

Module 2: Technical Marketing - This module gives the engineers a strong marketing orientation and shape their innovative high tech idea into the right product for the right customer, to further increase the chances of market success. This is very critical for engineers to develop paradigm pliancy and think in terms of the Whole Product, not just their generic technologies or products.

Module 3: High Tech Product Strategy - This state-of-the-art course module addresses the formulation of specific high tech product strategies to increase the probability of market success. These include Product Platform and Product Line Strategies; Differentiation and Price-based Competitive Strategies; Support Strategies based on Time, Cannibalization, and Global Product Development and Growth Strategies based on Innovation, Expansion ad Strategic Alliances.

Module 4: Technology Commercialization Strategies - This state-of the-art course is designed to develop the students' ability to apply the engineering and entrepreneurial processes to Technology Commercialization. This innovative, overview course will systematically cover the Technical, Marketing and Business aspects of the Technology Commercialization process in 18 steps through the 3 phases (Concept, Development and Commercial) and six stages (Investigation, Feasibility, Development, Introduction, Growth and maturity)

The Final Business Plan: Final Business Plan Write up and Presentation. As part of the proposed certificate requirement, the students would be required to write up a professional business plan and present it to the NASA / UCF Incubators and Technology Development / Commercialization Offices and also to Central Florida Investment Corporation and other interested VCs. Teams of two or three students will work on the development of the business plan to market an innovative new product or commercialize a promising technology, throughout the four-course program. 
This first-of-a-kind, pioneering course and holistic program address the formulation of specific strategies to significantly increase the probability of market and technical success. Entrepreneurship concepts and strategies developed empirically from the experiences of hightech companies are applied. These are more practical than theoretical and are intended to push systems engineering entrepreneurship to the cutting-edge. Through the incisive insights of leading systems engineering experts, entrepreneurs, numerous examples, and case studies / interactive discussions simulating the experiences of technical entrepreneurs, this comprehensive course series systematically covers almost all the issues aspiring technical entrepreneurs should consider in developing their new ventures., including funding, intellectual property, project management, timing, technological change, globalization, product positioning, and contingency planning, as well as marketing and financial considerations. Class sessions focus on the systems engineering principles and issues which must be faced in starting a new venture and the options which are available to the technical entrepreneur. Particular emphasis is placed on rigorous assessment of the technical and business merits of selected innovations through individual and group projects. VC and Angel-investor developed criteria is taken into consideration when selecting recipients for funds. Participation in other entrepreneur networking activities on campus and in the community is kept track of, encouraged and rewarded.

\section{The "Engineering Entrepreneur in the Spotlight" Experiential Seminar Series}

The Systems Engineering Entrepreneurship course series is complemented by another pioneering innovation in experiential entrepreneurship at Florida Tech - The "Engineering Entrepreneur in Spotlight" seminar series. In these seminars typically held twice a month, struggling/successful local technical entrepreneurs visit the class and present their business plan for critique and recommendations by the class. Once a month, these "Engineering Entrepreneur in the Spotlight" seminars are open to the public. Over the past three years, these seminars which have got wide pre- and post-event publicity in the local media, and have become an increasingly important networking forum for entrepreneurs, inventors investors, business service providers, students and faculty. As a result of these seminars a number of local business deals and alliances in high tech entrepreneurship have been consummated and Florida Tech students have secured careerenhancing opportunities with established and start-up companies as interns, co-op students, or permanent positions as founders, advisors or technical experts.

\section{Conclusions}

The initial impact of the nascent Systems Engineering Entrepreneurship program and experiential Entrepreneurship activities at Florida Tech has been remarkable.

Elements of the pioneering Systems Engineering Entrepreneurship course have been prototyped and tested in various formats such as seminars, short courses and as entrepreneurial topics in Systems Engineering courses. The Systems Engineering Entrepreneurship Course has got "excellent" reviews and student feedback in the first semester that it was offered. 
The "Engineering Entrepreneur in the Spotlight" seminar series featuring local entrepreneurs, innovators, inventors and, their research collaborators and entrepreneur networking / service providers such as Florida/NASA Business Incubation Center (FNBIC), Space Applications Technology Outreach program (SATOP), Technology Research and Development Authority of the State of Florida (TRDA), the Alumni Entrepreneur Alliance, The Space Coast EDC and other local organizations, have seen increasing attendance and have become an increasingly important networking and discussion forum for local entrepreneurs, inventors, business service providers, investors, students and faculty.

Two NCIIA grants, totaling about $\$ 40 \mathrm{~K}$ for Florida Tech have been central to the rapid increase in entrepreneurial participation by undergraduates in the College of Engineering. One of the grants funded entrepreneurial multi-university wireless senior design projects, while the other supported a series of Electrical and Computer Engineering Department senior design teams with entrepreneurial commitment. Additionally, Florida Tech has been an active partner of the NSFfunded Partnership for Innovation - Center for Entrepreneurship and Technology Commercialization (CENTECOM) along with UCF, USF and Florida A\&M University. The response to these grants has been extremely positive, with 7 of 13 entrepreneurial senior design teams in 2005 intending to launch businesses around their senior projects. Additionally, there were twelve graduate E-teams presenting their business ideas at the Engineering Entrepreneurship Business Idea Pitching competition. In 2005, Florida Tech was awarded a Advanced E-Team Grant for an innovative student project, emanating from the "Florida Tech Senior Design Project Commercialization and Entrepreneurship Program" which includes courses from the Systems Engineering Entrepreneurship course series. ${ }^{33,34}$

A contagious culture of engineering entrepreneurship and high degree of entrepreneurial awareness has been created on campus and in the Space Coast community. Two Florida Tech Student Entrepreneurs Clubs have been formed, affiliated to C-E-O (Collegiate Entrepreneur Organization) and SIFE (Students in Free Enterprise) respectively, with weekly meetings and a range of experiential activities. Some of the community-wide forums organized by the campusbased High Tech Business Accelerator such as the 4-session Intellectual Property workshop, the alumni entrepreneur panel discussion have seen record attendance from faculty, students and the Space Coast community. The SBIR workshops conducted by the Florida-NASA Business Incubation Center and the Space Coast EDC drew entrepreneurs and inventors from North, South and West Florida to the Space Coast. The NCIIA "Invention to Venture" workshop held in Orlando saw an exponential increase in attendees from the Space Coast. These activities have got considerable local media publicity.

With the Systems Engineering Entrepreneurship course and program enabling aspiring and struggling engineers-turned-entrepreneurs for higher degrees of entrepreneurial success with a deterministic approach (rather than a stochastic approach) it is anticipated that the locus of high tech entrepreneurship education will move from business schools to engineering schools. It appears that Engineering Entrepreneurship has emerged as a Killer App for the emerging Systems Engineering discipline 


\section{References}

1. Arora, Vijay K. and L. Faraone, " $21^{\text {st }}$ Century Engineer - Entrepreneur." IEEE Antennas and Propagation Magazine. Vol 45, No. 5, Oct 2003.

2. Hissey, T.W. "Education and Careers 2000." Proceedings of IEEE, 88, 8. August 2000.

3. Clough, G. Wayne. "The Engineer of 2020" - Main Plenary Session. ASEE National Conference, Portland, OR June 2005.

4. Chadwick, Kirstie: "Validating Your Opportunity." NCIIA Invention to Venture Workshop, Orlando, FL. Oct. 22, 2004.

5. Girvin, Josh: "Student Entrepreneurship." Florida Tech Engineering Entrepreneur in the Spotlight Seminar. Melbourne, FL. Feb. 25, 2005

6. National Academy of Engineering: The Engineer of 2020 - Visions of Engineering in the New Century. National Academies Press. 2004.

7. D'Cruz, Carmo and T. O'Neal: “Turning Engineers Into Entrepreneurs" Proceedings of the ASEM National Conference. Tampa, Oct 2002.

8. NCIIA. Advanced E-Team Proposal Guidelines. 2005. www.nciia,org.

9. Marken Communications. Engineer to CEO: The Development of Balance - Mar 1997 http://www.markencom.com/docs/01mar19.htm

10. Whittaker, John. "Engineers, Entrepreneurs and the Commercialization of Technology" PICMET 01 Conference Proceedings, Portland, OR. July 2001.

11. Gibb, Allan. "Entrepreneurship, Enterprise and Small Business: State of the Art ?" ed. Bohman and Pousette, Smaforetagsforskning 1 Tiden, $4^{\text {th }}$ Nordic SME Research Conference, Umea Universitet, June 1986

12. Staub-French, S. "Entrepreneurship and Engineering Management" - Engineers in Law and Business Development - February, 2004

13. Kao, John J., The Entrepreneurial Organization (Englewood Cliffs, N.J.: Prentice Hall, 1991).

14. Edwards, Robert. Entrepreneurs in High Technology: Lessons from MIT and Beyond (New York, Oxford: Oxford University Press, 1991)

15. Palmintera, D., J. Bannon, M. Levin and A. Pagan. "Developing High Technology Communities: San Diego". Report produced under contract to Office of Advocacy, U.S. Small Business Administration, Innovation Associates, Inc., Reston, Virginia 2000.

16. Pacific Partners Consulting Group. "An Economic Impact Study of Stanford University". Stanford. CA. 1997.

17. Jansen, C. and D. Jamison. "Technology Transfer and Economic Growth. Salt Lake City, Utah." The University of Utah. 1999.

18. Gartner, William B. "What Are We Talking About When We Talk About Entrepreneurship ?" Journal of Business Venturing, (5), 1990 pp. 15

19. D'Cruz, Carmo and P. Vaidyanathan "A Holistic Approach to Teaching Engineering Entrepreneurship and Technology Commercialization" - Proc. of ASEE National Conference, Nashville, Jun 2003

20. Kirzner, Israel. "The Entrepreneurial Process" in The Environment for Entrepreneurship, ed. Calvin A. Kent (Lexington Books, 1984) p. 41

21. Knight Russell M. "Can Business Schools Produce Entrepreneurs ? An Empirical Study," Journal of Small Business and Entrepreneurship, Vol. 5 (1) Summer 1987 
22. AUTM: Association of University Technology Managers Licensing Survey (1999). http://www.autm.net/surveys99A.pdf

23. Schreiberg, D. The Matchmakers. Stanford Today. (Jan/Feb 1998)

24.Wolfe, C., D. Adkins, and H. Sherman. Best Practices in Action - Guidelines for Implementing First-Class Business Incubation Programs. NBIA Publications, Athens, OH 2001.

25. Aley, J. "The Heart of Silicon Valley: Why Stanford.. Fortune. (July 7, 1997) pp 68-69.

26. Robinson, R. "Technology Transfer". Research Horizons (Sum/Fall 1998). Atlanta: Georgia Tech

27. Tornatzky, Louis, Y. Batts, N. McCrea, M. Lewis, and L. Quittman, "The Art and Craft of Technology Business Incubation.”. Southern Policies Board Report. Research Triangle Park, N.C. 1995.

28. Smilor, Ray, G. Kozmetsky, D.V. Gibson. Creating the Technopolis: Linking Technology Commercialization and Economic Development. Ballinger Publishing Co. 1988.

29. Gibson, David, G. Kozmetsky, R. Smilor. The Technopolis Phenomenon. Rowman and Littlefield. 1992.

30. Lacy, Robert Lacy: Ford - The Men and the Machine. Little Brown and Company. 1986.

31. Arora, Vijay. " $21{ }^{\text {st }}$ Century Engineer-Entrepreneur" - Proceedings of the 2001 ASEE Annual Conference. Albuquerque, NM June 2001.

32. Arnold, Michael: "Engineer to Entrepreneur - Making the Career Enhancing Transition" IEEE USA Sep 2002

33. D'Cruz, Carmo, Ken Ports and Muzaffar Shaikh, "Florida Tech Senior Design Commercialization and Entrepreneurship Program." Proceedings of the Portland International Conference on Management of Engineering and Technology (PICMET 2003), Portland, OR, July 2003

34. NCIIA: Curricular Models for Entrepreneurship (2003).

. http://apps.nciia.net/WebObjects/NciiaResources.woa/wa/View/CurricularModel?n=1000032

\section{APPENDIX}

\section{Course Overview:}

\section{Module 1: Systems Engineering Entrepreneurship}

This is a very resourceful course for skilled engineers and managers with creative product ideas, but limited knowledge of how to actually start building a company around the ideas. This cutting-edge course features Systems Engineering - based practical insights, tools, objectives, strategies and actions that one can apply to any stage of an entrepreneurial or intrapreneurial venture from initial idea to growth and profitability. The critical roles of marketing, finance and management are clearly explained as the entrepreneur learns practical and leading-edge system engineering approaches such as requirements engineering, project engineering, decision and risk analysis, systems modeling, systems integration, and system launch and quality engineering to bring products to market and grow the organization. Experiential guest lectures from industry experts and entrepreneurs on emerging technology trends, roadmaps, and standards processes, and interaction / networking opportunities with successful or struggling technical entrepreneurs, corporate intrapreneurs, venture capitalists, technology incubator directors, attorneys, financial advisors, consultants, etc. will be an added feature of this course. 


\section{Course Objectives:}

1. Develop an entrepreneurial idea into a commercially viable product line or business

2. Using a Systems Engineering based approach, solve the critical issues involved in product development, marketing and funding an entrepreneurial product from conception to profitable growth

3. Use Systems Engineering principles to develop multiple business operating structures for implementing efficient, long-range coordination, command and control

4. Apply high standards of company-wide quality engineering, project management, risk analysis

5. Develop a comprehensive understanding of the trends, roadmaps and standards processes of emerging technologies

6. Write a solid business plan/NCIIA E-Team proposal that attracts funding and keeps the entrepreneurial business on course

Course Outline: Key: GL=Guest Lecture; EOpps=Entrepreneurial Opportunities

1. Systems Engineering and Engineering Entrepreneurship $G L$ : Self Analysis and Strategic Visioneering

2. Requirements Engineering for Technical Entrepreneurs - Understanding Customer/Market Needs GL: EOpps through Technology Roadmaps / Standards Processes

3. Competitive Analysis for Engineering Entrepreneurs - Understanding the Competitive Environment and Protecting IP GL: EOpps in Software Systems Engineering

4. Business Systems Modeling for Engineering Entrepreneurship - Understanding the Basics of Accounting and Entrepreneurial Finance GL: EOpps in Optics Engineering

5. Product Development Process for Engineering Entrepreneurship GL: EOpps in Product Development and Improvement

6. Project Engineering for Engineering Entrepreneurship GL: EOpps in Civil Engineering

7. Decision and Risk Analysis for Engineering Entrepreneurship GL: EOpps in Engineering Consulting

8. Systems Integration for Engineering Entrepreneurship - The Business Plan GL: EOpps in Wireless Systems Engineering

9. Team Dynamics and Performance Assessment for Engineering Entrepreneurship GL: EOpps in Materials Engineering

10. System Launch Consideration for Engineering Entrepreneurs - Integrating Marketing/Sales GL: EOpps in Hydrogen Economy

11. Quality Engineering Consideration for Sustainable Engineering Entrepreneurship GL: EOpps in Systems Integration

12. Presentation of Final Business Plans or SBIR/STTR Proposals 